\title{
İsmail Kutluay Kardeşimize Rahmetle
}

\author{
With Mercy to Our Brother İsmail Kutluay
}

\section{Erol Yilmaz}

$\ddot{O}_{z}$

Yaklaşık iki yıldır küresel anlamda hayatı olumsuz etkilemeye devam eden COVID-19 pandemisi, en çok da aramızdan çekip aldı̆̆g sevdiklerimizle kanatıyor yüreklerimizi. Kimimiz babasını, kimimiz annesini, bazıları da çocuğunu ebediyete uğurladı bu illet sebebiyle. Akrabalarını, can dostlarını, kapı komşularını, meslektaşlarını, arkadaşlarını kaybedenler oldu. Hacettepe Üniversitesi Kütüphanecilik Bölümünün 1992 yılı mezunları da, çok sevdikleri arkadaşları Ísmail Kutluay'ı sonsuzluk âlemine yolcu etti, bu hastalı̆̆a bağlı olarak. Bu yazı, Ísmail 'in anısına, rahmete vesile olması duasıyla kaleme alınmış bir vefa yazısıdır.

Anahtar Sözcükler: Ismail Kutluay; Hacettepe Üniversitesi Kütüphanecilik Bölümü; COVID19; Koronavirüs pandemisi.

\begin{abstract}
The COVID-19 pandemic, which has continued to negatively affect life globally for about two years, bleeds our hearts mostly with our loved ones. Some of us sent off their father, some of us their mother, and some their children to the eternity, because of this disease. There were those who lost their relatives, buddies, neighbors, colleagues and friends. 1992 graduates of the Hacettepe University Department of Library Science also sent their beloved friend Ismail Kutluay to the realm of eternity, due to this disease. This article is a loyalty letter written in the memory of Ismail with the prayer that it will be a means of mercy.
\end{abstract}

Keywords: Ismail Kutluay; Department of Library Science, Hacettepe University; COVID-19; Coronavirus pandemic.

2019 yılının son günlerinde gündeme gelen ve kısa adı COVID-19 olan pandemi, başta sağlık olmak üzere, dünyayı çok çeşitli olumsuzluklar çerçevesinde etkilemeye devam etmektedir. Ekonomiden eğitime, spordan turizme kadar pek çok resmi iş ve işlemler ile toplumsal hayatı çok büyük oranda etkileyen ve bu bağlamda radikal değişimlere yol açan pandemiye bağl1 olarak yaşanan can kayıpları ise, doğudan batıya kuzeyden güneye 'büyük insanlık ailesi'ne en acı yüzüyle, ölümlerle dokunmaktadır.

İlk vakaların görüldüğü günlerden itibaren, çeşitli vesilelerle dünyanın gelişmiş ülkeleri tarafından da övgüyle anılan sağlık sistemimiz ve büyük bir özveriyle görev yapan sağlık

\footnotetext{
* Türkiye Büyük Millet Meclisi Araştırma Hizmetleri Başkanlığı, Ankara, Türkiye. E-posta: eryilmaz66@gmail.com

The Grand National Assembly of Turkey, Ankara,Turkey.E-mail: eryilmaz66@gmail.com
}

Geliş Tarihi - Received: 23.05.2021

Kabul Tarihi - Accepted: 24.05.2021

Yayımlanma Tarihi - Published: 30.06 .2021 
çalışanlarımız sayesinde en az can kaybı ve maddi zararla atlatılmaya çalışılmakla beraber, ülkemiz de pandemiden büyük oranda etkilendi. Ne yazık ki, etkilenmeye de devam ediyor.

Asla önemsiz olduğunu düşünmemekle birlikte, etkilediği başka alanlar bağlamında her şey bir yana, yaşanılan can kayıpları millet olarak canımızı yaktı, yakıyor. Önceleri, her akşam açıklanan turkuaz renkli tablodaki hasta ve can kayıpları üzüntü ve dualarla karşılanıyorken, süreç uzadıkça yakınlarımızdan da gönül hanelerimize ateş düşüren hastalık bilgileri ve ölüm haberleri gelmekte gecikmedi. Çember daraliyordu.

Önce aynı mahalledeki, ardından aynı binadaki komşularımızdan ve uzak akrabalarımızdan, bir zamanlar içerisinde bulunduğumuz çevrelerden yeni veya gecikmiş hastalık ve vefat haberleri yağmaya başladı evlerimize. Eski günleri hatırlayarak düştü ateşleri gönlümüze.

Derken yakın akrabalarımız ve hayatımızın çeşitli evrelerinde birlikte yol yürüdüğümüz arkadaşlarımızla ilgili acı haberler almaya başladık. Çocukluktan üniversite öğrenimine kadar çeşitli dönemlerde hayatımıza girmiş, acı-tatlı günlerde birlikte olduğumuz, bazılarıyla hayat şartları çerçevesinde yollarımız ayrılsa da, bir kısmıyla halen görüştüğümüz arkadaşlarımıza dair hazin mesajlar iletişim kanallarımıza düşüyordu artık. Çalan telefonları açmaya, sosyal medya hesaplarımıza girmeye korkar olmuştuk. Halen aynı tedirginliği, kaygıyı hatta korkuyu yaşıyor değil miyiz?

Birkaç ay önceydi...

Hacettepe Üniversitesi Kütüphanecilik Bölümünde birlikte okuyup, 1992 y1lında birlikte mezun olduğumuz ve o günden bugüne sürekli iletişim halinde bulunduğumuz arkadaşlardan biriyle bir konu vesilesiyle telefon görüşmesi yaparken, o gün şifa duasıyla konuşsak da bugün acıyla hatırladığım haberi söyleyiverdi arkadaşım kırık bir sesle.

Görüşmeyi yaptığımız günlerde Burdur Mehmet Akif Ersoy Üniversitesi Kütüphane ve Dokümantasyon Daire Başkanı olarak görev yapan İsmail Kutluay arkadaşımız da malûm ve acı etkileriyle meşhur illete yakalanmıştı.

Büyük bir üzüntüyle bir parça ön bilgi aldıktan sonra, kıymetli eşine ulaştım. Derin bir üzüntü yaşıyordu ve fakat güçlü bir tevekkül eşliğinde çok büyük bir umut taşıyordu. "İyi olacak Ísmail 'im, inanıyorum" diyor ve ekliyordu; "Ísmail'im çok iyi bir insandır, eski-yeni bütün arkadaşları hep aynı şeyi söylüyor, ne olur sizler de dua edin’”. Bugün dahi hatırladıkça, en çok da ağlamaklı bir sesle söylediği sözleri geliyor aklıma, içimi yaka yaka, yüreğimi kanata kanata; "n'olur, n'olur çok dua edin".

Çok dua ettim. Ellerimi Yüce Allah'a her açtığımda sağlık çalışanlarına ve tanıdığım tanımadığım bütün hastalara dua ederken, İsmail kardeşimi ismen andım. Sabahın seherinde, akşamın hüzün çöken dar vakitlerinde...

Onu her gün gören ve dolayısıyla gelişmeleri anbean izleyen eşinin büyük umutlar içinde verdiği bilgilerden de beslenerek, dönem arkadaşları olarak bizler de umut doluyduk. Dualarımızla hep yanında olduk İsmail'imizin. Ve her yeni günde telefonumuza, sosyal medya hesaplarımıza olumlu bir haberin düşmesini bekledik. 
Ne yazık ki, o telefonlar başka birçok haneye ve binlerce gönle olduğu gibi, bizlere de ac1 yüzüyle gösterdi kendisini. Kurtulamamış, yönünü bu tarafa çevirememişti İsmail kardeşimiz. Hissettiklerimi hissettirebilecek kadar güçlü değil kalemim ne yazık ki... Sadece içimin yandığını söyleyebilirim. İçimiz yandı sınıf arkadaşları olarak. 1988 yılının eylül ayından 1992 yılı haziran ayı sonuna kadar kare kare yaşananlar ve elimizde kalan acı ve ağır bir yokluk...

İsmail Kutluay, sevgili eşinin de ifade ettiği gibi, gerçekten iyi bir insandi.

O kadar iyiydi ki, öğrencilik hayatımız boyunca hiçbirimiz, hiçbir kişiyi incittiğini, kırdığını, üzdüğünü görmedik. "Öğrenciliğin şanındandır” ölçüsünün sınırları içerisinde dahi olsa, hiçbir hocamıza yönelik olarak uygunsuz bir davranışına veya sözüne de şahit olmadık İsmail'in.

Her zaman, her durumda ve şartta mutedil, orta halli bir yaklaşımı vardı. Hiçbir konuda aşırılığına şahit olmadık dört yıl süresince. O denli ortalama ve kuşatıcı bir kişiliğe sahipti İsmail kardeşimiz.

Genellikle hüzünlü, kelimenin tam anlamıyla mahzun bir yüz ifadesiyle dolaştığını görürdüm, koridor, bölüm, kütüphane vs. çeşitli ortamlarda. Bir aradayken de sürerdi bu hali genellikle. Onu hep duygusal bir ruh halinde izler ve "acaba bir derdi, bir sıkıntısı mı var" diye düşünür; ne var ki, üzmek, incitmek korkusuyla bir türlü soramazdım. Bazı arkadaşlara doğrudan sorsam da net cevaplar alamadığımı hatırlıyorum. O konuşmalar vesilesiyle, o zamanlar bugünkü haline göre epeyce soğuk, itici ve dahası gurbette olma duygusu veren Beytepe Kampüsündeki öğrenci yurdunda, kim bilir hangi ruh haliyle zaman zaman şiirler yazdığını öğrendim sevgili İsmail'in. Bu bilgiyi öğrendiğimde, şiirle ilgilenen birinin şair ruhuyla başkalarından daha çok duygu yoğunluğu yaşayabileceği düşüncesiyle bir nebze olsun rahatlamıştım.

Sevgili A. Faruk (Köker) ve Zeliha Göfer (Kılınç) ile birlikte hazırlayıcısı olduğu dönem yıllığının girişinde yer alan "Ayrılık” adlı şiiri de, onun duygusal haline yönelik önemli izler taşıyor;

Son gecemdi Beytepe'de ă̆ır ve yorgun kokulu

Bozkır rüzgârı penceremde

Alışık olmadı̆̆ım sigara tiryakiliği başladı gecede

Ve ayrılı̆̆ın acısını taşımaya başladım yüreğimde

Yıllar geldi aklıma, dört yıl

Yıllar ki, hüznün bereketini mutluluğa taşımış

Yıllar ki, açlığımı dost bilip yalnızlığımı türkü eylemiş

Yıllar ki, öfkeme kinime umut demiş

Yıllar ki, dört yıl

Dostlukların adı ve kolay yaşamanın tadiydı

Belki sevdaların kaynaştı̆̆ yarınların başlangıcıydı dört yıl

Sonrasi taze bir hayat

Ve yarınlar için yaşamlar başlayacak 
Hep yarınlar için

Ve yaşarken

Hepimiz yargılamaya başlayacă̆ız kendimizi

Ölene dek...

Y1llı̆̆ın “EN'ler bölümü”nde, “en karamsarımız”, “en iyi organizatörümüz”, “en çok uyuyanımız" ve "en zayıfımız" bölümünde yer alan sevgili İsmail Kutluay hakkında sınıf arkadaşlarının görüşlerinden oluşan şu ifadeler de onun ne kadar duygu yüklü iyi bir insan olduğunu -onlarca kalbin ortak sesi olarak- tarihe kaydetmiş durumda; "sevecen", "şair tabiatll”, "yufka yürekli”, "romantik”, "hassas”, "sessiz ve sakin”, “mükemmel kişilik”.

Ayrıca sorulara verdiği, "insanları sevmek ve gerçekçilik" (Hayata Bakışı), "insanları kırmak ve yanlış anlaşılmak” (En Çok Korktuğu), “çevreyi kirletenler ve sözünü tutmayanlar” (En Çok Nefret Ettiği) ve "yok edilen yeşil alanlar için mücadele etmek” (En Çok İstediği) şeklindeki cevapları da onun ne denli merhametli, duyarlı ve sevgi dolu bir insan olduğunu açık biçimde resmetmektedir.

Bununla birlikte, o genellikle mahzun, duygusal, hatta zaman zaman küskün bir yüzle gördüğüm/üz İsmail'in, çok sık olmasa da güldüğü zaman, esmer yüzünde bembeyaz gülücükler açardı birdenbire. Adeta kış ortasında rengârenk çiçeklerden oluşmuş bir bahçeye girmiş gibi hissedebilirdiniz o anlarda İsmail'in yüzüne baktığınızda. O kadar içten, o denli sıcacık gülerdi. Gülmek çok yakışırdı İsmail'in esmer yüzüne...

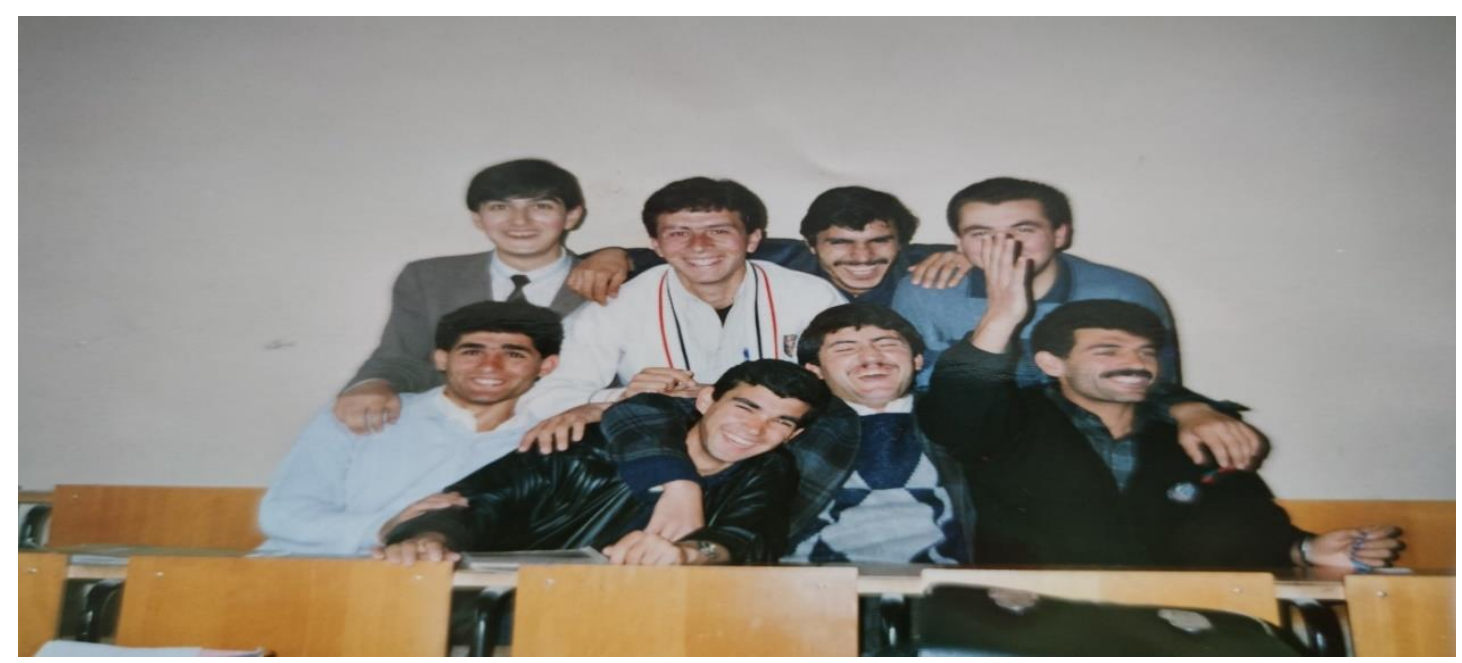

Görsel 1. İsmail Kutluay; ön sırada, soldan ikinci.

Söylemeye gerek var mı bilemiyorum ancak, ne kadar sıkıntılı, duygusal ve mahzun görünse de, aslî konumunun yani öğrenciliğinin gereğini yapmayı hiç ama hiç ihmâl etmedi İsmail. Bu noktada, hiçbir zaman akademik anlamda olumsuzluk yaşadığını hatırlamıyorum doğrusu.

Birçoğumuzun evinde, yani çekirdek ailelerde hastalığı yaşayanlar olsa da, belki hiç can kaybı yaşanmadı ancak, hemen ikinci halkadan başlayan akrabalarımız, meslektaşlarımız ve arkadaşlarımız arasından ebediyete irtihal edenler canımızı ziyadesiyle yaktı. Her biri, pandemi şartlarında kısıtlı katılımlarla gerçekleştirilen hazin törenlerle uğurlansalar da sonsuzluk 
âlemine, anıları hep yaşayacak kalplerimizde, birçok eşyada, fotoğraflarda ve nihayet, İsmail Kutluay kardeşimize dair gönül kırıntılarımı bıraktığım şu satırlar gibi ak kâğıtlar üzerinde.

Ruhun şâd olsun İsmail kardeşim...

Herkesle iyi geçinir, birleştirici bir çizgi sergilerdin. Bu güzel özelliğinin bugüne dahi yansımasıyla olsa gerek, birçoğu yıllardır görüşmeyen sınıf arkadaşların senin ardından seni anmak için kurdukları sosyal medya grubunda her gün buluşuyor, düne ve bugüne dair sohbet ediyor.

Hacettepe Üniversitesi Kütüphanecilik Bölümünde kısa ömrünün dört yılını paylaştığın arkadaşların, seni daima güzelliklerle, iyi duygularla, dualarla ve güldüğünde gülücükler açan yüzünle hatırlıyor, hatırlayacak.

Mekânın cennet olsun kardeşim.

Allah rahmet eylesin sana. 